\title{
Presence of Aldose Reductase Inhibitors in Tea Leaves
}

\author{
Itaru Sakai ${ }^{1}$, Shun-ichiro Izumi ${ }^{2}, *$ Takayo Murano ${ }^{2}$, Shinji Okuwaki ${ }^{2}$, Tsunehisa Makino ${ }^{2}$ and Takashi Suzuki ${ }^{1}$ \\ ${ }^{\prime}$ Bio-Team, Applied Technology Research Center, NKK Corporation, Kawasaki 210-0855, Japan \\ ${ }^{2}$ Department of Obstetrics and Gynecology, Tokai University School of Medicine, Bohsei-dai, Isehara 259-1193, Japan
}

Received August 21, 2000 Accepted December 21, 2000

\begin{abstract}
Water extract from commercial English tea has a potent inhibitory activity against human placenta aldose reductase (NADPH oxidoreductase, E.C.1.1.1.21.). Inhibitory activity was separated into five major fractions by one-step chromatography with a C-18 reverse phase column. The most active fraction was further subjected to reverse phase column chromatography. As a result, a well-known flavone-glycoside, isoquercitrin, was isolated as the most potent chemical. The inhibitory character of isoquercitrin for aldose reductase was a mix of uncompetitive and noncompetitive inhibitions, and its $\mathrm{IC}_{50}$ was $1 \times 10^{-6} \mathrm{M}$. In rat sciatic nerve tissue preparations, sorbitol accumulation in the presence of high concentrations of glucose $(30 \mathrm{mM})$ was inhibited by $38 \%$ at $5 \times 10^{-4} \mathrm{M}$ of isoquercitrin. The flavone-glycoside isoquercitrin is the active inhibitor of aldose reductase inhibitor present in English tea. Given the ability of aldose reductase inhibitors to prevent diabetic complications, an epidemiological study of the effect of tea consumption on the pathogenesis and progression of diabetic complications would be interesting.
\end{abstract}

Keywords: Aldose reductase, Enzyme inhibitor, Tea leaf, Human placenta, Diabetes

Recent clinical observations have shown that strict longterm control of blood glucose in diabetic patients significantly reduces the onset or progression of diabetic complications such as retinopathy, neuropathy and nephropathy $(1,2)$. While the mechanism underlying the transition to diabetic complications is unclear, some complications could be due to, in part, the hyperglycemia-activated polyol metabolic pathway catalyzed by aldose reductase (alditol: NADPH oxidoreductase, E.C.1.1.1.21), resulting in excessive accumulation of the glucose metabolite sorbitol in tissues. Supporting this assumption, sorbitol accumulation has been observed in the crystalline lens of experimental diabetic rats, resulting in induction of osmotic stress followed by tissue damage (3-6).

Since 1981, a number of aldose reductase inhibitors (ARIs) have been investigated ( $7-9$ ), and shown to prevent the development of experimental cataracts in animals, as well as the functional anatomic abnormalities of diabetic retinopathy and nephropathy. However, clinical trials of these ARIs do not clearly support the experimental results $(10-13)$. Of the ARIs evaluated, only tolrestat $(14,15)$ and epalrestat (16) were reported to have clinical efficacy in the early stages of diabetic neuropathy.

In the course of searching for ARIs in extracts of natural

*Corresponding author. FAX: +81-463-91-4343

E-mail: s-izumi@is.icc.u-tokai.ac.jp plants, we found inhibitory activity against aldose reductase in common English tea. In this report, we analyze and identify one of the active constituents of tea leaves and discuss the significance of this to diabetic complications.

\section{MATERIALS AND METHODS}

\section{Materials}

Fresh human placenta was obtained immediately after normal term delivery of an uncomplicated pregnancy. Mothers gave informed consent for use of placental tissue. The tissue was perfused with cold saline, excised of membranes and connective tissue, and then used immediately or stored at $-70^{\circ} \mathrm{C}$. Nicotinamide adenine dinucleotide phosphate (NADPH), D- and L-glyceraldehyde, and Dglucose were obtained from Wako Pure Chemical Industry (Tokyo). Protease inhibitors, antipain and leupeptin, were obtained from Peptide Institute, Inc. (Osaka).

\section{Preparation of aldose reductase}

A 30-mg sample of human placenta was homogenized in 5 vol of $10 \mathrm{mM}$ phosphate buffer, $\mathrm{pH} 7.4$, containing $1 \mathrm{mM}$ EDTA, $2 \mathrm{mM} \beta$-mercaptoethanol, and $2 \mu \mathrm{g} / \mathrm{ml}$ each of antipain and leupeptin. Following centrifugation of the homogenate at $105,000 \times g$ for $30 \mathrm{~min}$, the supernatant was diluted 2 times with distilled water, subjected to $40 \%$ ammonium sulfate precipitation and centrifuged. The resulting 
supernatant was subjected to $70 \%$ ammonium sulfate precipitation followed by centrifugation. The precipitate was

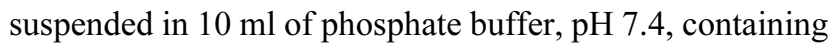
$2 \mathrm{mM} \beta$-mercaptoethanol and $2 \mu \mathrm{g} / \mathrm{ml}$ each of antipain and leupeptin; this was then used as an enzyme source of aldose reductase (17).

\section{Inhibition assay}

Routine assay of aldose reductase inhibition was carried out in a reaction mixture containing $50 \mathrm{mM}$ sodium phosphate, $100 \mathrm{mM}$ ammonium sulfate, $0.1 \mathrm{mM}$ NADPH, $5 \mathrm{mM}$ glyceraldehyde, enzyme and sample (inhibitor) in a total volume of $1 \mathrm{ml}$. The reaction was initiated by the addition of glyceraldehyde and monitored at $340 \mathrm{~nm}$ for $5 \mathrm{~min}$ at $25^{\circ} \mathrm{C}$ with a Ubest-50 Spectrophotometer (Jasco, Tokyo). As a control, absorbance at $340 \mathrm{~nm}$ was monitored in the absence of inhibitor.

\section{Isolation and determination of ARI of tea leaves}

Ten tea-bags (from Lipton, Brooke Bond or Nitto) were soaked in 11 of hot water $\left(90-95^{\circ} \mathrm{C}\right)$ for $30 \mathrm{~min}$. The extract was left on ice overnight, centrifuged, and the clear supernatant was concentrated by lyophilization. The lyophilate was dissolved in $100 \mathrm{ml}$ of distilled water and applied to a C-18 reverse phase column $(5.5 \times 30 \mathrm{~cm}$, ODS-80TS; Tosoh, Tokyo) equilibrated with $20 \%$ acetonitrile containing $0.1 \%$ trifluoroacetic acid. The column was washed with 3 bed volumes of $20 \%$ acetonitrile and eluted with 5 bed volumes of a linear gradient of $20-40 \%$ acetonitrile containing $0.1 \%$ trifluoroacetic acid. Four-milliliter fractions were collected. Aliquots of $200 \mu 1$ were withdrawn from every other fraction, lyophilized, and examined in the inhibition assay.

For further purification of inhibitor(s), one of the active fractions from the C-18 column chromatography, fraction D (Fig. 1), was lyophilized and subjected to analytical reverse phase column chromatography $(0.46 \times 25 \mathrm{~cm}$, TSKgel ODS80TM; Tosoh). The bound materials were eluted with 5 bed volumes of a linear gradient of $30 \%$ to $40 \%$ acetonitrile containing $0.1 \%$ trifluoroacetic acid. The major fraction was lyophilized and subjected to structural analysis by infrared spectrometry (IR), nuclear magnetic resonance spectrometry (NMR) and mass spectrometry (MS).

\section{Determination of sorbitol in nerve tissue}

Sciatic nerve tissues were excised from rats and soaked in $3 \mathrm{ml}$ of Krebs-Ringer bicarbonate buffer, $\mathrm{pH} \mathrm{7.2,} \mathrm{con-}$ taining $30 \mathrm{mM}$ glucose, in the presence or absence of ARI. At the indicated time, tissues were removed, placed on a filter paper to remove adherent fluid, weighed and then homogenized in $0.5 \mathrm{ml}$ of cold $8 \%$ perchloric acid. Following centrifugation of the homogenate, the clear supernatant was recovered, neutralized with $2 \mathrm{~N} \mathrm{KOH}$ and assayed for sorbitol. Sorbitol content was determined enzymatically by the sorbitol dehydrogenase reaction $(18,19)$. The amount of sorbitol is proportional to the formation of NADPH as measured by the increase in extinction at $340 \mathrm{~nm}$. Results were statistically analyzed by one way ANOVA with the Bonferroni/Dunn test as the post hoc test, and a difference is significant when $P \leq 0.05$ vs control.

\section{RESULTS}

\section{Isolation of inhibitor from tea-leaf extract}

A typical elution profile of ARIs on the C-18 reverse phase column is shown in Fig. 1. The hot water extract of tea leaves, which exhibited a potent inhibitory activity, was separated into 5 fractions (Fig. 1, designated A, B, C, D and E). Initially, partial extraction of the inhibitors from tea extract was attempted using organic solvents including ethylacetate, acetone or butanol; unfortunately, the inhibitory activity remained in the aqueous phase and not the organic phase. In addition, since pretreatment with these organic solvents showed no advantage over subsequent C-18 reverse phase column chromatography, pretreatment procedures were deleted. Among the five active fractions, fraction D (Fig. 1) exhibited the highest specific inhibitory activity; this fraction was pooled, concentrated, and applied to an analytical reverse phase column. The activity was eluted in one peak with a negligible peak on the shoulder (data not shown). The active fractions were pooled and subjected to structural analyses by IR, NMR and MS. ARI in this fraction was identified as the well-known flavoneglycoside isoquercitrin (Fig. 2).

\section{Characteristics of isoquercitrin}

The potency of isoquercitrin to human aldose reductase appeared equal to that of the known ARI, ONO-2235 (Epalrestat) (Fig. 3). The $\mathrm{IC}_{50}$ was $1 \times 10^{-5} \mathrm{M}$. When an inhibitory mechanism is elucidated, the binding site(s) of the inhibitor on the enzyme should be considered: binding sites of either the substrate or cofactor (NADPH) or elsewhere on the enzyme. First, the possibility of interference with the substrate binding site was examined (Fig. 4). Isoquercitrin at $1 \times 10^{-6} \mathrm{M}$ exhibited a parallel line with the control, characteristic of uncompetitive inhibition. Increasing the inhibitor to $3 \times 10^{-6} \mathrm{M}$, however, resulted in convergence of the $\mathrm{K}_{\mathrm{m}} \mathrm{S}$ in the reciprocal plot to show noncompetitive inhibition. Our results indicate that the enzyme is inhibited in a mixed manner and not by binding to the site of the substrate.

Secondly, the possibility of competitive binding of the inhibitor to the site of NADPH binding was examined with fixed concentrations of substrate and inhibitor (Fig. 5). At lower concentrations of inhibitor $\left(1 \times 10^{-5} \mathrm{M}\right)$, the inhibitory manner was uncompetitive, whereas at higher con- 


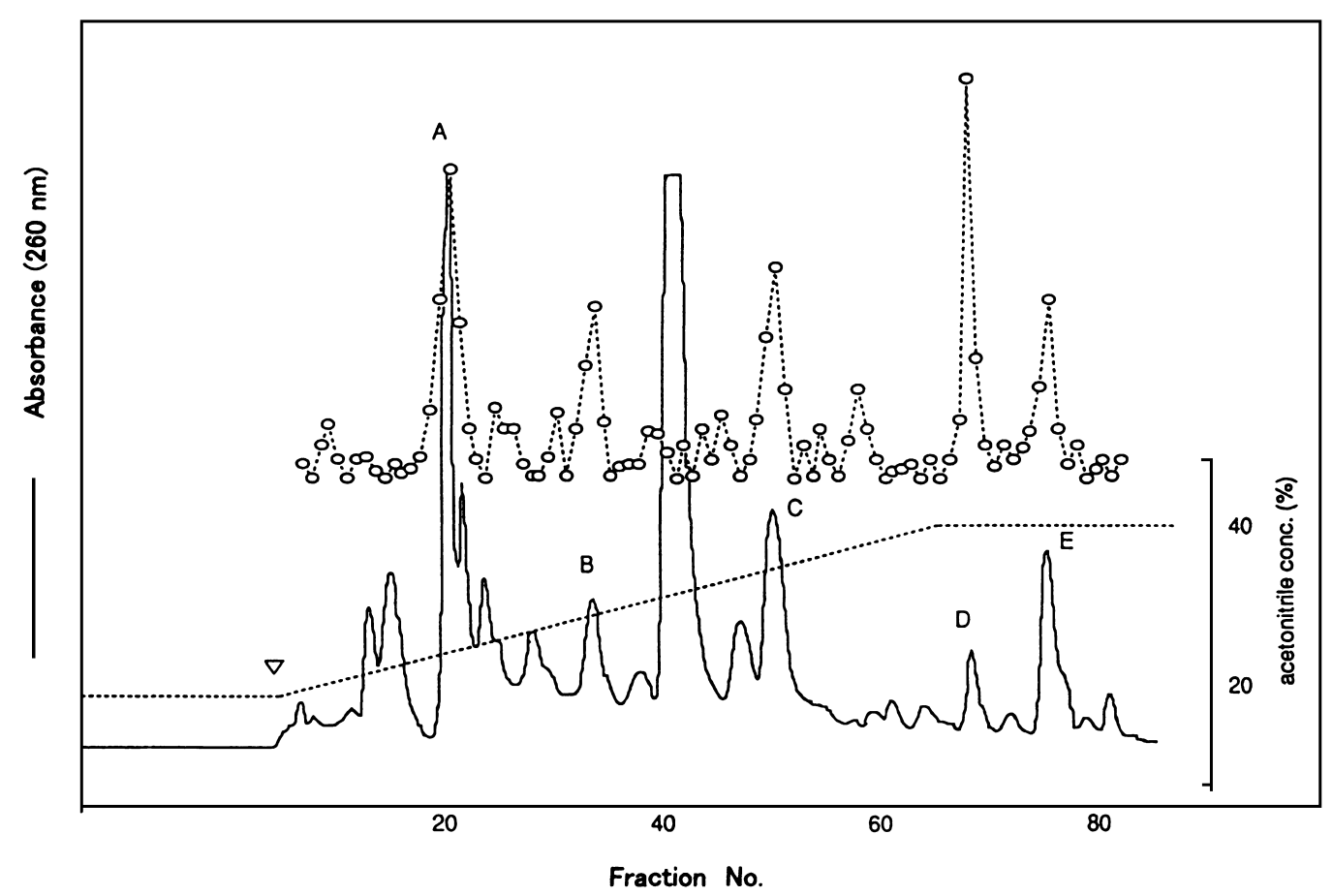

Fig. 1. Typical elution profile of aldose reductase inhibitors of tea extract. Water extract of tea leaves was applied on a C-18 reverse phase column. After washing with $40 \mathrm{ml}$ of $20 \%$ acetonitrile $(\nabla)$, inhibitors were eluted with linear gradients of $20 \%$ to $40 \%$ acetonitrile (---). Elution profile was monitored by absorbance at $260 \mathrm{~nm}(-)$, and inhibitory activities of fractions were monitored by the human placenta aldose reductase assay (o---o).<smiles>O=c1c(O[Ga]Cl)c(-c2ccc(O)c(O)c2)oc2cc(O)cc(O)c12</smiles>

Fig. 2. Chemical structure of isoquercitrin.

centrations, it was noncompetitive. These results indicate that inhibition occurred at a site independent from that of the cofactor. ONO-2235 (20) and sorbinil (18) are ARIs with a similar mixed type of inhibition. So far, all ARIs which have been subjected to enzyme kinetic studies have demonstrated activity by binding at a site independent of the substrate or cofactor (NADPH) binding sites $(20-22)$. However, structural analysis of crystallized human aldose reductase by electron microscopy has not revealed the inhibitor binding site (23). Nevertheless, these inhibitors have been shown to be effective in preventing some of the complications of diabetes in animal models.

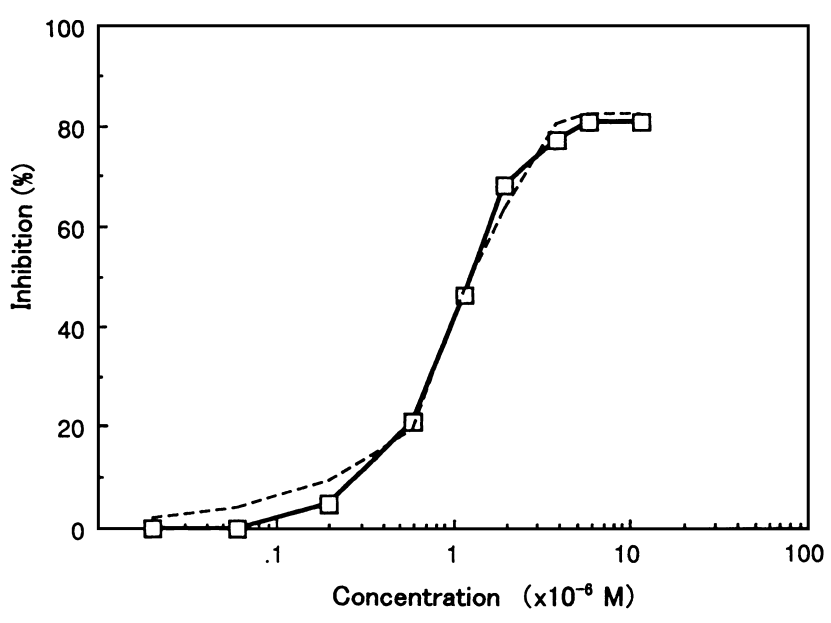

Fig. 3. Inhibition of human placenta aldose reductase. Aldose reductase activities in the presence of various concentrations of isoquercitrin ( $\square$ ) or ONO-2235 (-----) were measured as described in Materials and Methods. Reductase activity in the absence of inhibitor was defined as $100 \%$.

Effect of isoquercitrin on sorbitol accumulation in sciatic nerve tissue

When sciatic nerve tissue is incubated in $30 \mathrm{mM}$ glucose, sorbitol accumulated linearly over time. Sorbitol levels increased 11-fold in $4 \mathrm{~h}$ and 15 -fold in $6 \mathrm{~h}$ (data not shown). 


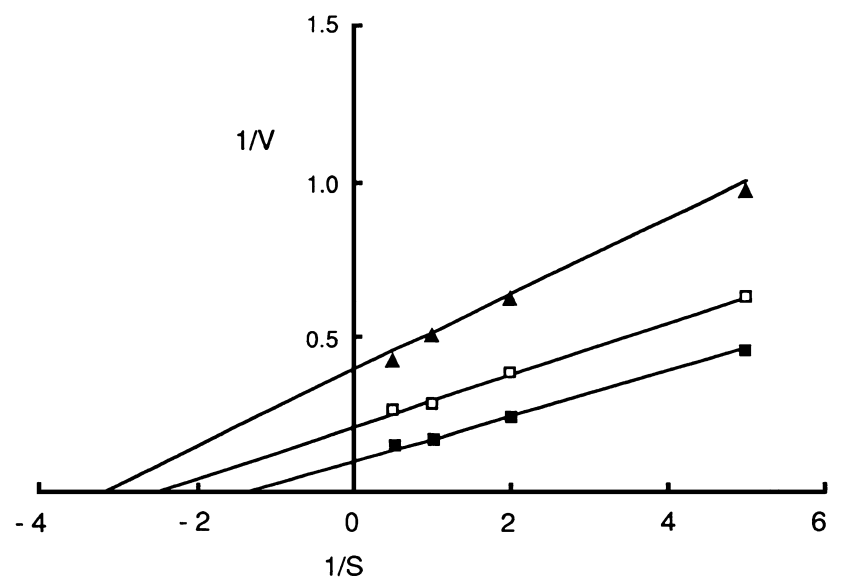

Fig. 4. Effect of isoquercitrin on the Lineweaver-Burke plot of aldose reductase activity. The ordinate and abscissa represent the reciprocals of initial velocity and glyceraldehyde concentration, respectively. Activity was measured in the absence ( $\square$ ) or presence of isoquercitrin at concentrations of $1 \times 10^{-6} \mathrm{M}(\square)$ or $3 \times 10^{-6} \mathrm{M}$ $(\mathbf{\Delta})$.

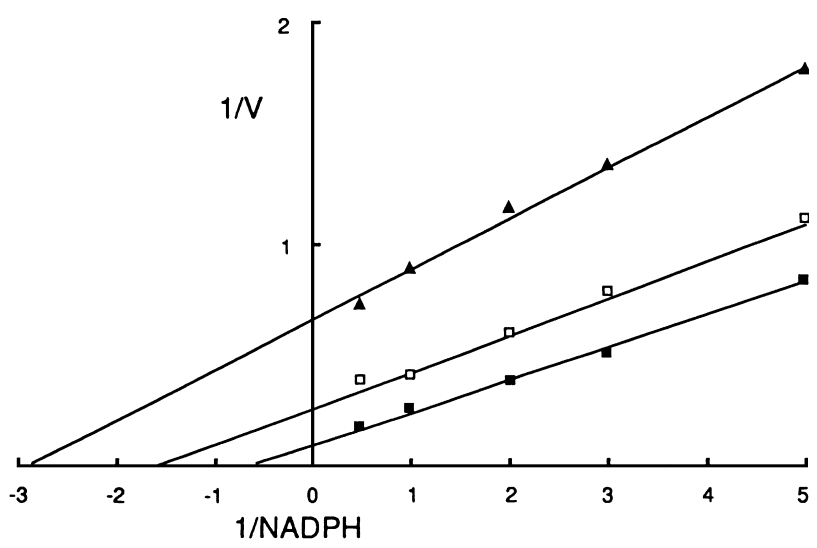

Fig. 5. Effect of isoquercitrin on the Lineweaver-Burke plot of aldose reductase activity. The ordinate and abscissa represent the reciprocals of initial velocity and NADPH concentration, respectively. Activity was measured in the absence ( $\mathbf{\square})$ or presence of isoquercitrin at concentrations of $1 \times 10^{-6} \mathrm{M}(\square)$ or $3 \times 10^{-6} \mathrm{M}(\boldsymbol{\Delta})$.

In the presence of isoquercitrin, sorbitol accumulation was inhibited in a dose-dependent manner (Fig. 6). At 5 $\times 10^{-4} \mathrm{M}$, sorbitol accumulation was inhibited by $38 \%$. In comparison with ONO-2235, which exhibits an $\mathrm{IC}_{50}$ of $0.39 \mu \mathrm{g} / \mathrm{ml}$, isoquercitrin was less potent.

\section{DISCUSSION}

In this study, we demonstrated ARIs in common English tea. One of these inhibitors was the flavone-glycoside isoquercitrin. Since the potency of isoquercitrin is equivalent to that of ONO-2235 in enzyme assays of aldose reductase, we expected the same inhibitory activity as ONO-2235 on

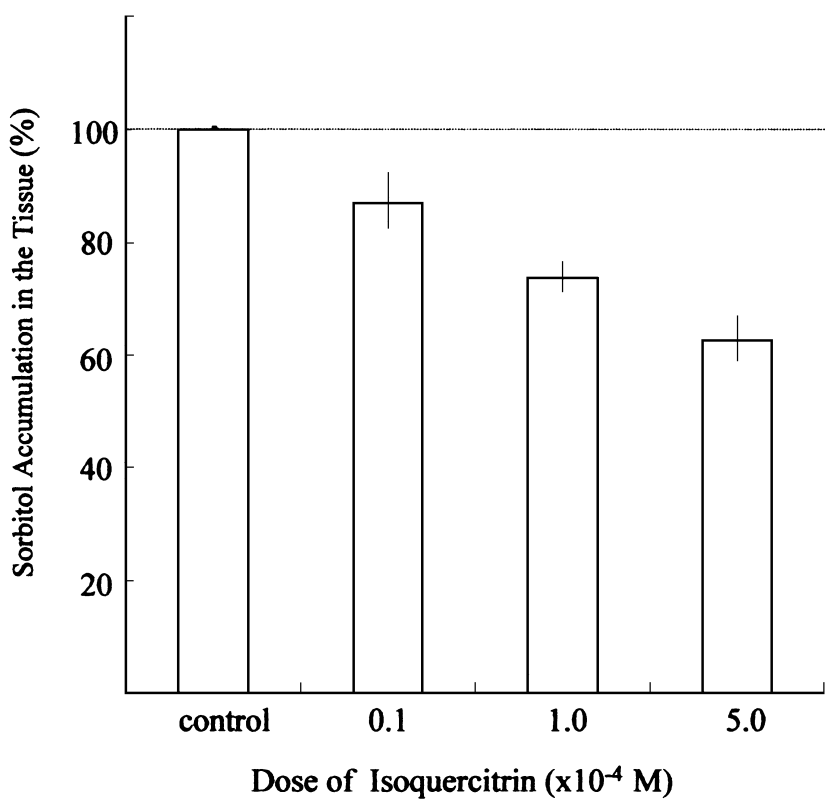

Fig. 6. Effect of isoquercitrin on sorbitol accumulation in nerve tissue. Isolated rat sciatic nerve tissue was incubated in the presence of $30 \mathrm{mM}$ glucose with or without $5 \times 10^{-4} \mathrm{M}$ of isoquercitrin for $4.5 \mathrm{~h}$, and sorbitol content in tissue was measured as described in Materials and Methods. Sorbitol accumulation (mean \pm S.D., $n=4$ ) in the tissue was significantly inhibited at the higher concentrations of isoquercitrin than $1 \times 10^{-5} \mathrm{M}(P \leq 0.05$ vs control $)$.

sorbitol accumulation in nerve tissue. Supposing its minimal effective dose is $1 \mathrm{mg}$ /day, we can expect its pharmacological benefit from daily consumption of more than 10 tea bags. However, isoquercitrin had much less activity than ONO-2235, presumably due to its low lipophilicity and poor permeability, as noted by its poor solubility in organic solvents (see our purification procedure). Despite its relatively weak activity as an ARI in tissue, in combination with other bioactivities of isoquercitrin $(24,25)$, tea consumption might have a beneficial chronic effect. There are no epidemiological data on the relationship between tea consumption and the pathogenesis or progression of diabetic complications. It would be interesting to determine whether drinking tea daily affects sorbitol accumulation and the pathogenesis of diabetic complications.

\section{REFERENCES}

1 Feldman EL, Stevens MJ and Greene DA: Pathogenesis of diabetic neuropathy. Clin Neurosci 4, 365 - 370 (1997)

2 Santiago JV: Lessons from the diabetes control and complications trial. Diabetes 42, 1549 - 1554 (1993)

3 Van Heyninger R: Formation of polyols by the lens of the rat with "sugar" cataract. Nature 184, 194 - 195 (1959)

4 Raskin P and Arauz-Pacheco C: Treatment of diabetic retinopathy: a view for the internist. Ann Intern Med 117, 226 - 233 (1992) 
5 Phillips SA, Mirrlees D and Thornalley PJ: Modification of the glyoxalase system in streptozotocin-induced diabetic rats. Effect of the aldose reductase inhibitor Statil. Biochem Pharmacol 46, $805-811$ (1993)

6 Reddy VN, Lin LR, Giblin FJ, Lou M, Kador PF and Kinishita $\mathrm{JH}$ : The efficacy of aldose reductase inhibitors on polyol accumulation in human lens and retinal pigment epithelium in tissue culture. J Ocul Pharmacol 8, 43 - 52 (1992)

7 Tomlinson DR, Willars GB and Carrington AL: Aldose reductase inhibitors and diabetic complications. Pharmacol Ther 54, 151 - 194 (1993)

8 Inukai S, Agata M, Sato M, Naitou A, Matsukawa $\mathrm{H}$ and Goto M: Characterization of a novel aldose reductase inhibitor, TAT, and its effects on streptozotocin-induced diabetic neuropathy in rats. Jpn J Pharmacol 61, 221 - 227 (1993)

9 Malamas MS, Hohman TC and Millen J: Novel spirosuccinimide aldose reductase inhibitors derived from isoquinoline1,3-diones: 2-[(4-bromo-2-fluorophenyl) methyl]-6-fluorospiro [isoquiniline4 $(1 H), 3^{\prime}$ pyrrolidine]-1,2',3,5' $(2 H)$-tetrone and congeners. J Med Chem 37, 2043 - 2058 (1994)

10 Krans HM: Recent clinical experience with ARIs. J Diab Comp 6, $39-44$ (1992)

11 Greene DA: Effects of ARIs on the progression of nerve fiber damage in diabetic neuropathy. J Diab Comp 6, 35 - 38 (1992)

12 Arauz-Pacheco C, Ramirez LC, Pruneda L, Sanborn GE, Rosenstock $\mathrm{J}$ and Raskin P: The effect of aldose reductase inhibitor, ponalrestat, on the progression of diabetic retinopathy. J Diab Comp 6, 131 - 137 (1992)

13 Ranganathan S, Krempf M, Feraille E and Charbonnel B: Short term effect of an aldose reductase inhibitor on urinary albumin excretion rate (UAER) and glomerular filtration rate (GFR) in type 1 diabetic patients with incipient nephropathy. Diabete Metab 19, 257 - 261 (1993)

14 Passariello N, Sepe J, Marrazzo G, De Cicco A, Peluso A, Pisano MC, Sgambato S, Tesauro P and D'Onofrio F: Effect of aldose reductase inhibitor (tolrestat) on urinary albumin excretion rate and glomerular filtration rate in IDDM subjects with nephropathy. Diabetes Care 16, 789 - 795 (1993)

15 Ven Gerven JM, Lemkes HH and Von Dijk JG: Long-term effects of tolrestat on symptomatic diabetic sensory polyneuropathy. J Diab Comp 6, 45 - 48 (1992)

16 Horita J, Kakuta H, Sakamoto N, Tomino A, Kroda M and Inagawa A: Clinical trials of 5-[(1E,2E)-2-methyl-3-phenylpropenylidene]-4-oxo-2-thioxo-3-thiazolizineacetic acid (ONO2235). Gendai Iryo 18, Suppl III, 421 - 466 (1986) (in Japanese)

17 Hayman S and Kinoshita JH: Isolation and properties of lens aldose reductase. J Biol Chem 240, 877 - 882 (1965)

18 Bergmeyer HU, Gruber W and Gutman I: D-Sorbitol. In Methods of Enzymatic Analysis, Edited by Bergmeyer HU, Vol 3, pp 1323 - 1326, Academic Press, New York (1974)

19 Malone JI, Knox G, Benford S and Tedesco TA: Red cell sorbitol, an indicator of diabetic control. Diabetes 29, $861-864$ (1980)

20 Terashima H, Hama K, Yamamoto R, Tsuboshima M, Kikkawa R, Hatanaka I and Shigeta Y: Effects of a new aldose reductase inhibitor on various tissues in vitro. J Pharmacol Exp Ther 229, $226-230$ (1984)

21 Ward WH, Cook PN, Mirrlees DJ, Brittain DR, Preston J, Carey F, Tuffin DP and Howe R: (2,6-Dimethylphenylsulphonyl) nitromethane: a new structural type of aldose reductase inhibitor which follows kinetics and uses an allosteric binding site. Biochem Pharmacol 6, 2115 - 2123 (1991)

22 Kato K, Nakayama K, Mizota M, Miwa I and Okuda J: Properties of novel aldose reductase inhibitors, M16209 and M16287, in comparison with known inhibitors, ONO-2235 and sorbinil. Chem Pharm Bull (Tokyo) 39, 1540 - 1545 (1991)

23 Wilson DK, Bohren KM, Gabbay KH and Quiocho FA: An unlikely sugar substrate site in the $1.65 \mathrm{~A}$ structure of human aldose reductase holoenzyme implicated in diabetic complication. Science 257, 81 - 84 (1992)

24 Yokozawa T, Dong E, Kawai Y, Gemba M and Shimizu M: Protective effects of some flavonoids on the renal cellular membrane. Exp Toxicol Pathol 51, 9 - 14 (1999)

25 Somanadhan B, Smitt UW, George V, Pushpangadan P, Rajasekharahn S, Duus J, Nyman U, Olsen CE and Jeroszewski JW: Angiotensin converting enzyme (ACE) inhibitors from Jasminum azoricum and Jasminum grandiflorum. Planta Med 64, $246-250$ (1998) 